\title{
RETOMANDO A PRÁXIS NA FORMAÇÃO DO ASSISTENTE SOCIAL NA UNIVERSIDADE FEDERAL DO PARANÁ - UFPR: Setor Litoral.
}

Édina Mayer Vergara ${ }^{1}$ - Universidade Federal do Paraná.

Congratulo-me com o Curso de Serviço Social e o Setor Litoral de nossa Universidade Federal do Paraná neste bonito momento de implantação da Revista Resistência Litoral como um passo importante na sedimentação e contribuições deste Curso para além da Região onde se insere, fortalecendo o pensamento crítico e científico acerca da realidade social. Busco apresentar aqui alguns recortes da realidade vivida, entendendo-a como totalidade concreta, histórica e contraditória, mas que, para ser contada, carece de recortes que são fruto de inúmeras conexões vividas entre os anos 2010-2018, quando da minha aposentadoria.

Desde 2006 as intencionalidades e vivências progressistas da proposta pedagógica que estava sendo implantada no Setor Litoral se aproximaram de minha vida através das aulas e pesquisas sob responsabilidade da Prof Maria Isabel da Cunha do Programa de Pós Graduação em Educação da Universidade do Vale do Rio dos Sinos - UNISINOS que, à época, assessorava a implantação da proposta pedagógica do Setor litoral. Quando busquei o concurso junto ao curso de Serviço Social deste Setor da UFPR via claramente uma Educação Superior sendo construída com base na práxis, onde estudantes, docentes, profissionais técnicos e gestores, fossem todos interessados nos saberes locais, nas demandas sociais, na concretude do tempo histórico onde ocorre a imersão da instituição educacional.

Trago aqui elementos de uma memória histórica, de uma vivência práxica impossível de relatar em primeira pessoa na sua totalidade concreta, em sua intensidade, contradições, movimentos, transformações, com os múltiplos sujeitos acadêmicos que a construíram, com diferentes áreas de conhecimento, com as diferentes formas de imersão e aprendizagens previstas no Projeto Político Pedagógico desse Setor e, fundamentalmente, sem os sujeitos das comunidades com as quais todas essas oportunidades se concretizaram. Parto do fato de que não será uma redação que me contemple, porque neste momento não é possível trazer para o texto a problematização dessa práxis coletiva com os que a construíram, sustentaram e

\footnotetext{
1 - Doutora em Educação pela Universidade do Vale dos Sinos - Unisinos. Professora aposentada pelo curso de Serviço Social da Universidade Federal do Paraná - Setor Litoral.
} 


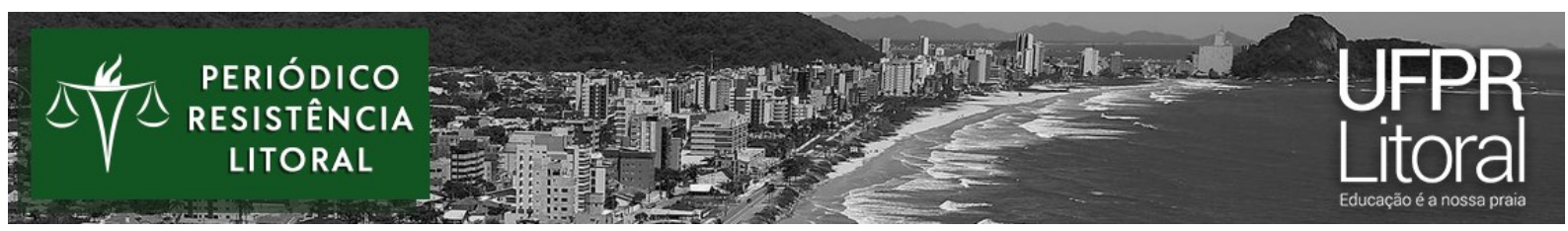

avaliaram, culminando em uma formação acadêmica interdisciplinar, interinstitucional e intersetorial que nos atravessou a existência por pelo menos cinco anos.

Considerando o fato de que formação profissional em Serviço Social é comprometida com uma leitura histórico-crítica da realidade concreta, logo visa dialogar e corresponsabilizarse pelas demandas sociais locais e regionais. $\mathrm{O}$ trabalho acadêmico implica os princípios da instituição onde se ancora, bem como a história de luta e proposições da formação específica, ainda que interdisciplinar, que lhe confere a feição. Pensar o trabalho acadêmico triangulado pelo ensino-pesquisa e extensão, é pensá-los comprometidos com os projetos societários que superem as assimetrias sociais, entendendo a inegociável contribuição do conhecimento e do acervo e avanço técnico-científico, social e politicamente comprometidos.

Entendendo que as atividades acadêmicas de pesquisa e de extensão dão vida e materialidade ao ensino - que, no Setor Litoral tem o enfoque voltado para a aprendizagem quando mobilizam possibilidades socioeducionais como forma de luta política para as transformações que nos inspiram como categoria desde o nosso Projeto Ético Político.

Deste modo, a proposição de formação em Serviço Social - em suas diferentes dimensões - está posicionada contra as injustiças da questão social ${ }^{2}$ que subalternizam boa parte da população. É preciso, continuamente, desnaturalizar o olhar, torná-lo cada vez mais crítico frente às violações de direitos, acentuadas pelos abismos sociais num fenômeno planetário e catastrófico como uma pandemia, como e quais violações ocorrem. Assim, urge pensar a formação acadêmica no Serviço Social, e para além dela, numa perspectiva crítica do humano em seu lugar e este como sujeito de transformação de si, do lugar e do território para um projeto societário mais equânime. Desnaturalizar o olhar é perguntar, problematizar, indagar criticamente a realidade, para que se fortaleça, como afirma Iamamoto, "O reconhecimento das atividades de pesquisa e o espírito indagativo como condições essenciais ao exercício profissional" (2001, p.56).

Assim, mesmo antes da minha ação docente neste Curso de Serviço Social havia em mim uma apropriação profunda das intencionalidades do PPP do Setor Litoral, fui conhecendo e compreendendo a riqueza material desta proposta na vivência de cada Fundamento TeóricoPrático - FTP, Interação Cultural-Humanística - ICH, acompanhamento de estágio, de Projetos

\footnotetext{
${ }^{2}$ A questão social entendida como o conjunto de todas as sequelas produzidas pelo capitalismo com sua divisão da sociedade em classes, em contradição e em luta. Desde este modo de produção se expressa de diferentes formas de acordo com a correlação de forças em jogo a cada tempo e território.
} 
de Atividades - PA, horas-atividades, orientação de TCCs, de projetos ou programa de extensão e pesquisa, vendo nestes espaços convergência e potências para o propor e agir como assistente social e educadora. E como vivemos cada espaço pedagógico que o Projeto PolíticoPedagógico - PPP - do Setor Litoral nos conferia, nos oportunizava como liberdade e responsabilidade de aproximação máxima com a materialidade das desigualdades da Região onde veio ser parte.

Reafirmo que este Setor se tornou muito especial em minha vida por possuir um Projeto Político Pedagógico diferenciado pois seus espaços pedagógicos fortalecem territórios concretos de vivências concretas e cotidianas com os sete municípios de seu entorno, vivências que têm interesse no desenvolvimento sustentável e que muito contribuíram para que os meus últimos anos na docência universitária tenham sido encharcados da vida comunitária de povos tradicionais caiçaras. Seria uma nova oportunidade de ser docente no Serviço Social, aquela que iria trazer a Instituição inteira de forma muito clara com uma Educação tão firmemente voltada para propósitos tão valiosos à nossa profissão.

Desta forma, vou destacar uma, das muitas atividades acadêmicas, vividas intensamente que me marcou como ente ativo e propositivo de um PPP institucional, que transcendia o Curso, mas que não seria operado sem ele. Inicialmente nominado como Movimento Águas de Março, o mesmo foi uma das muitas respostas gestadas no Setor Litoral frente às múltiplas sequelas trazidas pelas enchentes e deslizamentos ocorridos no Litoral no mês de março de 2011 que assolou quatro das sete cidades litorâneas. Este Movimento foi possível pela maturação de muitas pessoas nas suas imersões no PPP do Setor, em processos de conhecer e compreender nosso entorno e com ele assumir compromissos defendidos pela própria razão de existir deste Setor Universitário de educação pública.

De forma concreta e datada, essa riqueza de tantas aprendizagens se iniciou com a Turma 2009 de Serviço Social em um Módulo de Fundamentos Teórico-Metodológicos e Históricos do Serviço Social III, sob minha responsabilidade à época; construímos um caminho pedagógico baseado em aprendizagem investigativa participante, tendo as expressões concretas da questão social e os contornos das políticas sociais como entrelace para a leitura, proposição e intervenção na formação profissional diante daquela situação de emergência pública.

Propusemo-nos a maximar as potências do conhecer-compreender-propor e agir nas diferentes instâncias pedagógicas do PPP do Setor Litoral em conjunto com as teorias e competências caras à formação do nosso Curso, aproximando-as com as demandas que se 


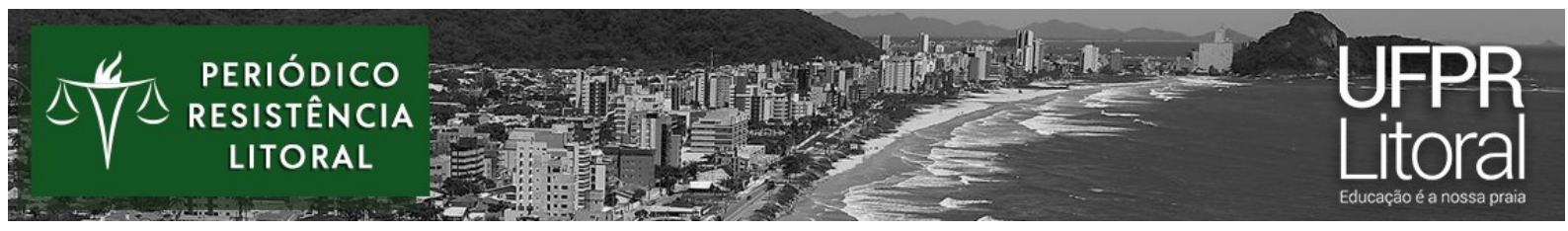

colocavam naquela emergência social arrasadora.

O município de Morretes, tanto em sua área rural quanto urbana, estava severamente atingida e, através da professora Jussara Araújo, que articulava o Setor junto ao município, fomos nos aproximando dos espaços de acolhimento das famílias que perderam suas casas por soterramento. Nosso planejamento se iniciava por ouvi-las em suas urgências e com elas estabelecermos possibilidades, mediações para o enfrentamento do quadro colocado.

Assim nos autorizamos, pois o Setor estava comprometido com seu lugar desde os princípios de seu Projeto Político Pedagógico - PPP - que dão eixo ao ethos da UFPR Litoral, quais sejam:

a) o comprometimento da Universidade com os interesses coletivos;

b) a educação como totalidade;

c) a formação discente pautada na crítica, na investigação, na pró-atividade e na ética, capaz de transformar a realidade. (PPP 2008, p.9)

Considerar tais princípios se soma com nossos compromissos éticos e políticos e exercício de nossas competências profissionais, previstas na Lei $\mathrm{N}^{\circ} 8.662$ de 1993, que são meios para responder efetivamente às demandas urgentes da população, portanto, tanto as competências quanto a intervenção profissional fazem sentido na sua relação histórica com a realidade concreta.

As pessoas que compunham o Movimento Águas de Março problematizavam permanentemente, semana após semanas formas de interagir com as difíceis demandas das populações desterritorializadas - da zona rural para a urbana - em função da perda total de suas moradias e espaços de plantio.

No correr dos meses, depois daquele março de 2011, o Movimento Águas de Março agregou outros cursos, professores, técnicos e estudantes, dessa forma a UFPR Litoral respondia às complexidades da questão social se organizando em caráter de urgência junto à UFPR, organizando um Programa de Extensão Universitária intitulado Formação e Organização Comunitária para a Geração e Gestão Cooperada e Sustentável de Trabalho e Renda (registro UFPR/PROEC 114/12). Se constituiu como uma reação mais amadurecida à capilaridade das múltiplas expressões da questão social, agravadas pela catástrofe ambiental ocorrida no dia 11 março de 2011 . O Programa de extensão propunha projetos de extensão para a meliponicultura, fitoterápicos, tijolos ecológicos e artesanato local, em convênio da 


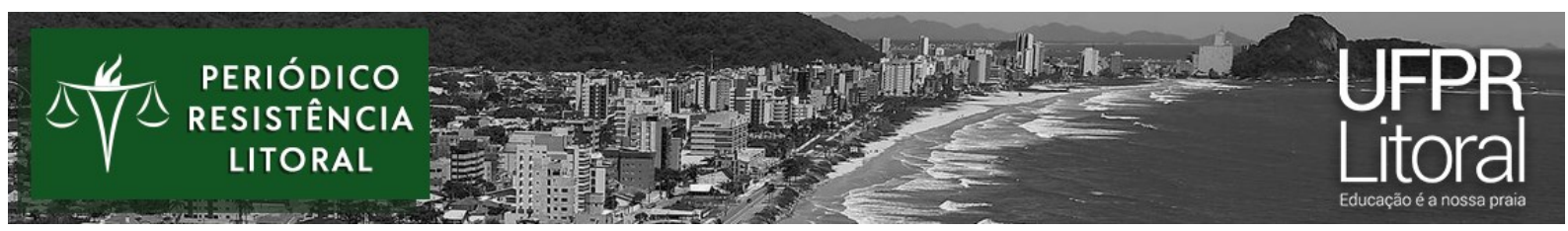

Universidade com a Prefeitura Municipal, a Cooperativa Motirõ e a Secretaria de Estado de Ciência e Tecnologia - SETI.

Estávamos organizados. As potencialidades eram reais, mas apesar de captarmos, não conseguimos acessar recursos públicos para efetivar nenhum dos projetos, mas mesmo assim persistimos. Mesmo assim, muitos estudantes, técnicos e professores da UFPR continuaram a efetivar boa parte dos projetos pois a liberdade pedagógica para a práxis nos diferentes espaços pedagógicos previstos do PPP do Setor Litoral, assim nos permitia, o que acontecia de forma planejada, avaliada e interdisciplinar tanto na academia quanto nos diferentes lugares com os quais interagímos: Estação das Artes e Fundação Malucelli com dois ICHS semanais, Secretarias Municipais da Assistência, Agricultura, Cultura e Educação com vivências de horas-atividades, estágios curriculares, pesquisas, e georreferenciamento. Parcerias com o Assentamento Movimento Sem Terra - MST, escolas urbanas e do campo, Comunidades, Associações Sociais e Religiosas, Casa Lar, Pastoral da Criança, Promotoria de Justiça, ativistas, dentre outros que possam, por equívoco, não serem citados.

A quase totalidade das famílias que tiveram sua situação social acentuadas pelos desastres naturais já viviam em condições de desigualdade gritantes antes disso, e assim compreendendo, pensávamos em viabilizar modos de identificarem seus direitos e modos próativos de acesso aos mesmos e gestão de suas vidas e ambiente em que habitam.

Nossa proposição passava pela sistematização, implantação e implementação de um Observatório de Geotecnologias Sociais que permitisse diagnosticar as demandas socioambientais dando vistas às garantias de acesso e efetivação dos direitos sociais (principalmente assistência social, educação, habitação, saúde e segurança alimentar). Assim poderíamos apoiar um sistema produtivo para o desenvolvimento sustentável local com a geração de trabalho e renda (em especial construções sustentáveis, artesanato caiçara, produção agro-extrativista de base agro-ecológica, alimentos, pesca e aquicultura) considerando o perfil e demandas de formação das populações. Novamente buscamos recursos públicos e mais uma vez, apesar de termos sido contemplados com o edital nacional do Ministério de Ciência e Tecnologia com um valor superior a três milhões de reais para a implantação de Centro VT em Morretes, jamais acessamos qualquer valor, novamente por questões insterinstitucionais.

Entendemos que nosso caminho possível era capacitar a população cada vez mais para conhecerem modos de materializar seus direitos, em especial através da organização social, do controle social com permanente formação para o conhecimento de seus direitos e potenciais. 


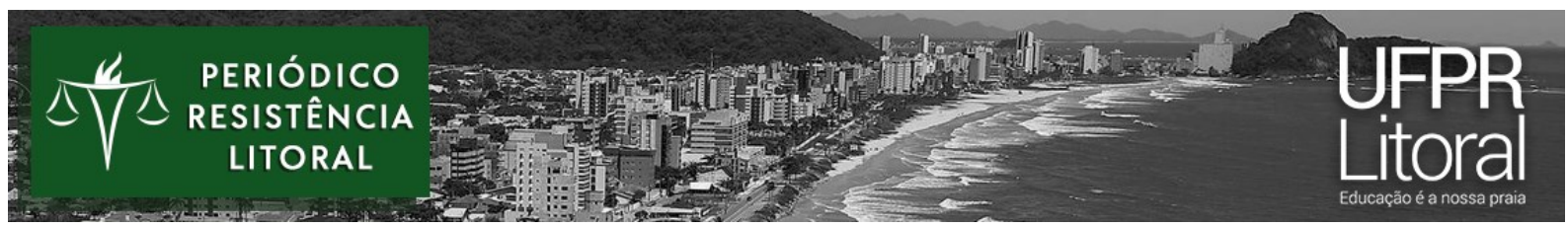

Assim, como em nossas pesquisas - um permanente conhecer e compreenderinterdisciplinares sempre esteve no nosso olhar comum buscar visibilizar as desigualdades sociais. O acréscimo do uso das Tecnologias da Informação - T.Is para a elaboração da cartografia social foi um avanço neste sentido; com essa cartografia foi possível problematizar os fluxos legalmente instituídos para a gestão cidadã dos direitos sociais buscando estratégias concretas para o desenvolvimento social baseado no empoderamento instrumental tecnológicocientífico e comunitário como ação política para a consolidação de processos de justiça social.

Assim com nosso grupo interdisciplinar visava consolidar um instrumental de domínio público para o trabalho social com o empoderamento metodológico de gestão popular de direitos sociais sustentada pela visibilização de cartografias sociais (em especial no âmbito territorial municipal), apresentando ainda as dinâmicas legais para a organização comunitária, bem como os Programas Federais e de outras instâncias financiadoras; esta trilogia: cartografia social - modos de organização comunitária - fontes financiadoras - permitindo instrumentalizar os sujeitos sociais para exercerem suas potências como sociedade civil e gestores na materialização de seus direitos. Assim, o uso das Tecnologias de Informação nos permitiu dar corporeidade aos direitos silenciados, invisibilizados, violados e nos fortalecemos como grupo na aquisição de competências tecnológicas e interdisciplinares.

\section{AMPLIANDO AS PARCERIAS}

Neste contexto, entre 2012-2013, vários debates sobre o futuro da presença da UFPR Litoral em Morretes foram construídos para além do coletivo que sustentava a proposta de forma direta $^{3}$, ora com a gestão do Setor, ora com a gestão do município e neste caso também com colegas professores do curso de Ciências Sociais da UFPR em Curitiba, com o qual implementamos um Programa de extensão intitulado Programa de Desenvolvimento Urbano e Regional - PDUR, em convênio com o Ministério das Cidades - MC - e ao curso de Gestão e Processos Educacionais para a Diversidade e Inclusão - GPEDI, vinculado à Secretaria de Educação Continuada, Alfabetização, Diversidade e Inclusão - SECADI do Ministério da Educação - MEC.

\footnotetext{
${ }^{3}$ Reitero que este coletivo era composto por estudantes, professores, técnicos, terceirizados, pessoas da comunidade, gestores e organizações, bem como minha impossibilidade de elencar os nomes de pessoas, cursos ou organizações sob pena de omissão de algum ente que dele participou.
} 


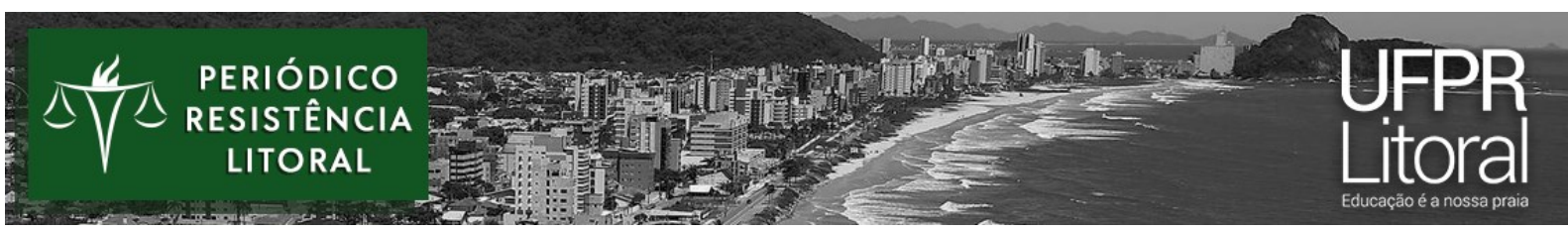

Os limites extremos de não acessarmos recursos que conquistamos legitimamente para a concretização dos direitos dessas famílias, nos fazia buscar alternativas para além das fontes institucionais o que para nosso grupo foi possível pela sua força metodológica, interdisciplinar, intersetorial, técnica e academicamente sedimentada, ética e politicamente posicionada: buscar incessantemente formar para enfrentar as sequelas excludentes da questão social e a partir do compromisso da Educação Superior.

Cada vez mais entendíamos que a identificação de demandas, planificação, captação de recursos e gestão coletiva de projetos para desenvolvimento comunitário, pela própria comunidade organizada, são meios que permitem solidificar a autonomia de suas vidas, o cuidado mútuo e do espaço em que vivem, para além da Seguridade Social, com nuances que permitam acesso, permanência e autonomia através da inclusão produtiva longeva, sustentável ambiental e socialmente, podendo vivenciar propostas de retomada e desenvolvimento local; isto se torna fundamental em Regiões como a Litoral Paranaense e o Vale do Ribeira, com suas populações tradicionais e não raramente em vulnerabilidade social, requerendo que a Educação Superior contribua com articulações: intersetorial com as políticas públicas, interdisciplinar e interseccional com o conhecimento e interinstitucional entre os executivos locais, as escolas, as Universidades , a rede de proteção que compõem o Sistema de Garantia de Direitos e a sociedade civil organizada e suas comunidades.

\begin{abstract}
A garantia de direitos, no âmbito de nossa sociedade, é de responsabilidade de diferentes instituições que atuam de acordo com suas competências: as instituições legislativas nos diferentes níveis governamentais; as instituições ligadas ao sistema de justiça - a Promotoria, o Judiciário, a Defensoria Pública, o Conselho Tutelar — aquelas responsáveis pelas políticas e pelo conjunto de serviços e programas de atendimento direto (organizações governamentais e não governamentais) nas áreas de educação, saúde, trabalho, esportes, lazer, cultura, assistência social; aquelas que, representando a sociedade, são responsáveis pela formulação de políticas e pelo controle das ações do poder público; e, ainda, aquelas que têm a possibilidade de disseminar direitos fazendo chegar a diferentes espaços da sociedade o conhecimento e a discussão sobre os mesmos: a mídia (escrita, falada e televisiva), o cinema e os diversificados espaços de apreensão e de discussão de saberes, como as unidades de ensino (infantil, fundamental, médio, superior, pós-graduado) e de conhecimento e crítica (seminários, congressos, encontros, grupos de trabalho). (BAPTISTA, 2012, p. 187)
\end{abstract}

Assim víamos força vital em nossa proposição de Observatório de Geotecnologias Sociais, que sistematizasse e publicizasse informações que mapeavam e caracterizavam as fragilidades na efetivação das diferentes políticas públicas locais, em especial aquelas sociais, portanto, inegociáveis em seu cumprimento e que ainda raramente geram efeitos de emancipação, seja pelo não atrelamento dos seus demandatários ao mundo do trabalho ou da 
gestão menos colonizada e mais autônoma de acesso aos direitos que lhe são devidos. E assim, através do PDUR foi possível cooperar para a construção do georreferenciamento do município, centenas de mapas sociais que permitiam enxergar em "imagens que falavam mais de mil palavras", as condições de existência, de mobilidade, de acesso a serviços, dentre tantas mais que interessavam às demandas comunitárias, pois a violação aos direitos sociais se torna abissal quando as possibilidades de gestão dos mesmos não são compartilhadas entre poder público e sociedade civil, isto se deve inclusive pelo frágil conhecimento das comunidades sobre os modos de fazê-lo. Trabalhamos a relação Universidade-Comunidade através de fóruns sistemáticos para a busca de alternativas de resoluções coletivas.

Desde a universidade pública com um PPP libertário nos permitiu viver, experimentar, problematizar a realidade concreta, nos seus próprios movimentos, contradições e totalidade, sem nunca esquecer por quê, com quem e para quê nossa participação acontecia. Participação práxis, interdisciplinar com a ativa importância de todos os sujeitos que compunham nosso coletivo. Nossa experiência de participação coletiva nos ensinou que - no local das gentes e ambiente que queremos sejam justos e sustentáveis - há potência, esperanças e concretudes de empoderamento e resolutividade dos problemas e desejos ali vividos.

O Movimento Águas de Março nunca deixou de ser, teve diferentes nomes, se organizou mais institucionalmente sob forma de pesquisa e extensão, mas também foi o cotidiano do PPP do Setor Litoral pois foi espaço de ICHs, PAs, estágios, horas-atividades, resultou em TCCs e proposições técnicas. Foi lugar das graduações, de especialização, foi parceiro de associações, foi comunidade, foi insterdisciplinaridade, foi sempre e vivamente aprendizagens... mas também foi atravessado por jogos de poder e interesses diversos, foi frustração, sofreu críticas, muitas críticas, raras vezes colocadas nos nossos espaços semanais de planejamento e avaliação, no sentido de superação dos limites, equívocos e fragilidades.

Este relato é sumamente pessoal, optei em não citar nenhum curso, profissional, instâncias parceiras ou pessoas porque todos foram imprescindíveis e seria injusto algum esquecimento. São muitos planejamentos, relatórios, TCCs, artigos, mapas, intervenções, vídeos, fotos, e-mails, diários, todos contam uma parte de um todo impossível de traduzir; este foi um processo construído por pessoas que tinham como horizonte um inédito viável maior, que ainda ecoa em muitas situações que precisariam ser contadas pelos próprios componentes participantes desse Movimento, desde aquelas águas.

Conhecemos - compreendemos - propusemos - agimos e nunca esqueceremos. 
Vivemos nossa formação em Serviço Social atravessados pelos fundamentos e propósitos do nosso Projeto Ético-Político Profissional e do PPP deste nosso Setor Litoral que nos move, comove e nos inspira a continuarmos na inegociável luta por materialização e dilatação de direitos.

"A coisa principal da vida não é o conhecimento, mas o uso que dele se faz."

Talmude

\section{REFERÊNCIAS}

BAPTISTA, Myrian Veras. Algumas reflexões sobre o sistema de garantia de direitos In. Serv. Soc. Soc. n. 109. São Paulo: Cortez. Jan./Mar. 2012

IAMAMOTO, Marilda. O Serviço Social na contemporaneidade. São Paulo:Cortez, 2001.

RPC. Rede Paranaense de Comunicação (14/03/2011). Morretes, PR, decreta calamidade pública; 8 mil estão fora de casa. http://g1.globo.com/pr/parana/noticia/2011/03/morretesdecreta-calamidade-publica-8-mil-pessoas-estao-fora-de-casa.html. Acessado em 13/07/2021

UFPR. Universidade Federal do Paraná. (2008b). Projeto Político Pedagógico.Matinhos:UFPR.http://www.litoral.ufpr.br/portal/wpcontent/uploads/2015/02/PPP-UFPR-LITORAL_Set2008_Alteracao_Dez-2008.pdf. Acessado em $02 / 07 / 2021$ 